\title{
BMJ Open The association between combined oral contraceptive use and overweight/ obesity: a secondary data analysis of the 2016 Ethiopia Demographic and Health Survey
}

\author{
Melese Linger Endalifer (D) , ${ }^{1}$ Gedefaw Diress (D) , ${ }^{1}$ Amanuel Addisu (D) , \\ Bedilu Linger $^{2}$
}

To cite: Endalifer ML, Diress G, Addisu A, et al. The association between combined oral contraceptive use and overweight/obesity: a secondary data analysis of the 2016 Ethiopia Demographic and Health Survey. BMJ Open 2020;10:e039229. doi:10.1136/ bmjopen-2020-039229

- Prepublication history for this paper is available online. To view these files, please visit the journal online (http://dx.doi. org/10.1136/bmjopen-2020039229).

Received 08 April 2020 Revised 30 November 2020 Accepted 02 December 2020

D Check for updates

(C) Author(s) (or their employer(s)) 2020. Re-use permitted under CC BY-NC. No commercial re-use. See rights and permissions. Published by BMJ.

${ }^{1}$ Department of Public Health, College Of Health Science, Woldia University, Woldia,

Ethiopia

${ }^{2}$ Department of Pharmacy, College Of Medicine and Health Science, Wollo University, Dessie, Ethiopia

Correspondence to Melese Linger Endalifer; melselinger@gmail.com

\section{ABSTRACT}

Objectives In this study, we aimed to assess the association between combined oral contraceptive (OC) use and overweight/obesity among Ethiopian adult women of reproductive age.

Design, setting and participants The data were extracted from the 2016 Ethiopia Demographic and Health Survey; these data were collected from nine regions and two city administrations. We analysed the data from a total of 11018 women aged 18-49 years who met eligibility criteria.

Main outcome measures We employed WHO criteria to classify the body mass index of women. Specifically we tested the association between combined $\mathrm{OC}$ utilisation with overweight/obesity after controlling for confounding variables.

Result The prevalence of combined $\mathrm{OC}$ utilisation was $1.7 \%$ and the prevalence of overweight/obesity was $8.6 \%$ among adult women of reproductive age. Use of combined $\mathrm{OC}$ increases the odds of overweight/obesity by two times among adult women of reproductive age after controlling for potential confounders (adjusted $\mathrm{OR}=1.902$ (1.064-3.399)).

Conclusion In conclusion there is significant association between combined $\mathrm{OC}$ use and overweight/obesity. The findings have important implications for policymakers to design evidence based policy approachs to obesity prevention for women and at large for government to recognise the negative consequences of combined $\mathrm{OC}$ on women health.

\section{INTRODUCTION}

Recently the prevalence of overweight/ obesity increased both in the developed world and the developing world. WHO defines overweight and obesity as abnormal or excessive fat accumulation that may impair health, ${ }^{1}$ which is associated with many chronic diseases, such as diabetes mellitus, heart diseases, hypertension and some forms of $_{\text {cancer. }}{ }^{2-4}$

\section{Strengths and limitations of this study}

- In the multivariable analysis, confounders were controlled.

- The sample size was large and adequate; this increases precision of the findings

- The ethical clearance fulfilled national protocols.

- Household economic status was assessed through the Wealth Index.

- There is an absence of variables such as duration of combined contraceptive use in the data set.

In 2016, more than 1.9 billion adults (18 years and older) were overweight. Of these over 650 million were obese. ${ }^{1}$ Previously, overweight/obesity was considered as a problem of high-income countries; now this has emerged in low-income and middle-income countries also, particularly in urban settings. ${ }^{5}$

A study which analyses the demographic and health survey data of 23 sub-Saharan African countries revealed that the pooled prevalence of overweight was $15.9 \% .{ }^{6}$ Obesity leads to metabolic disorder ${ }^{7}$; specifically during pregnancy, its effects result in adverse neonatal outcome, caesarean section ${ }^{8-10}$ and maternal morbidity. ${ }^{11}$ The effect of obesity does not end with this; it also results in breast and ovarian cancers. ${ }^{12}$

The risk of obesity was higher among users of hormonal contraceptives due to the effect of progesterone. Progesterone induces appetite or facilitates anabolism and oestrogen aggravates the accumulation of fat in the cell or adipose tissue. It was seen that the effect increased as the duration of hormonal contraceptive utilisation increased. ${ }^{13}$ Similarly a study conducted in Kenya and Myanmar indicates that overweight/obesity 
was significantly correlated with hormonal contraceptive use. $^{1415}$

A study conducted among premenopausal women in Korea and Spain revealed that oral contraceptives (OCs) have a significant association with overweight/obesity. ${ }^{16} 17$ In contrast other researchers concluded that OC had no association with obesity or weight gain. ${ }^{18}$ Besides; an evidence drawn from a systematic review concluded that there is nosufficient scientific evidence to generalize whether combined oralcontraceptive have significant association with overweight/obesity or not. ${ }^{19}$

Most studies conducted previously have shown that obesity affects the efficacy and effectiveness of combined OCs, ${ }^{20-25}$ but but other studies showed that obesity had no effect on COC efficacy and effectiveness. ${ }^{26-28}$

Additionally some researchers have pointed out the effects of OC on ovarian cancer, polycystic ovary syndrome and cardiovascular disease. ${ }^{29-32}$

In the Ethiopian context different researchers have extensively identified the determinant factors of overweight/obesity, ${ }^{33-42}$ but none of them depicted the correlation between combined OC use and overweight/ obesity.

Generally there is controversy on the effect of combined OC use on the development of overweight/obesity. Therefore we intend to assess the association between combined OC use and overweight/obesity among adult women of reproductive age.

\section{METHODS AND MATERIALS}

\section{Study design and population}

The 2016 Ethiopian Demographic Health Survey (EDHS) was designed to provide up-to-date estimates of key demographic and health indicators in Ethiopia. The data were collected from nine regions and two city administrations. A detailed description of the study design and methodology of the 2016 EDHS was found elsewhere. ${ }^{43}$ In brief, a stratified two-stage random sampling design was used to collect the data from a nationally representative sample. In the first stage, a total of 645 enumeration areas (EAs) (202 in urban areas and 443 in rural areas) was selected through probability proportional to EA size. In the second stage, 28 households per cluster was systematiclly selected with an equal probability of selection. Data were obtained from the DHS programme website: https://www.dhsprogram.com.

A total of 15683 women aged 15-49 years was interviewed in the 2016 EDHS. Those women with missing data on the question related to the outcomes of interest and other covariates were excluded. In this paper, we restrict our analytical sample to 11018 non-pregnant women aged $18-49$ years (figure 1 ).

\section{Measurement of height and weight of women}

The weights and heights of the mothers were measured with standard weighing and height scales. The weight of the women was measured to the nearest $100 \mathrm{~g}$ on a

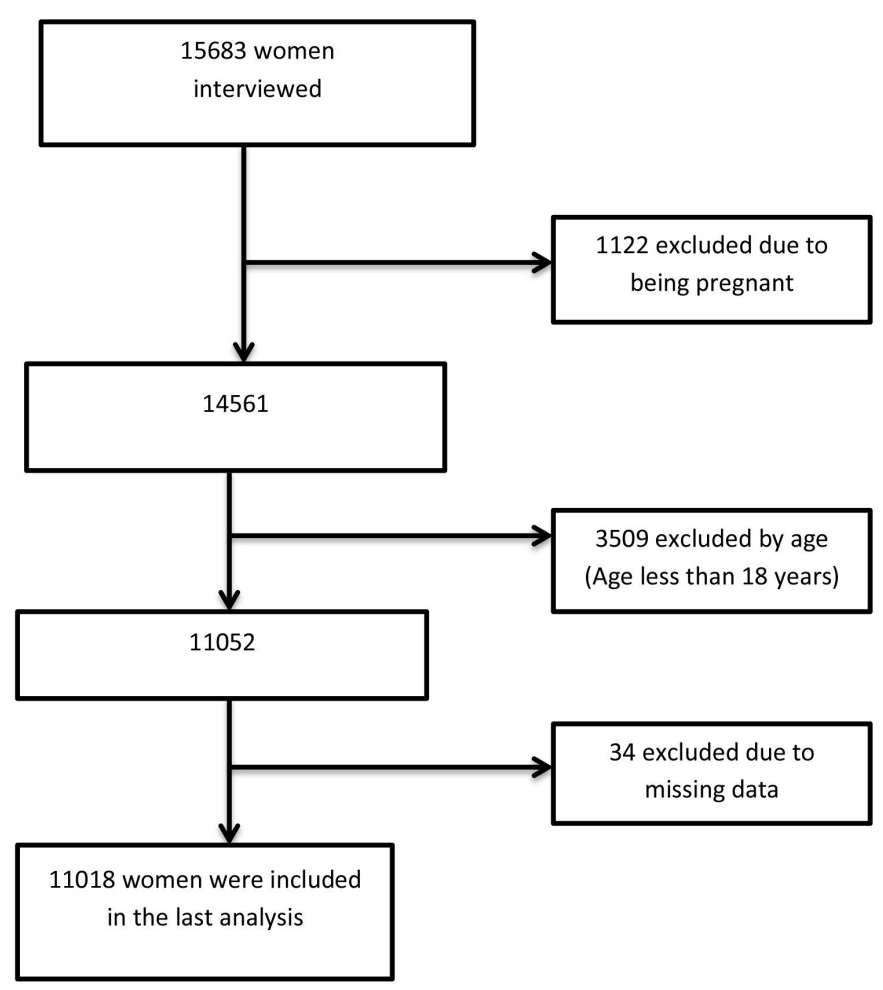

Figure 1 Flow diagram of selection of study participants.

calibrated portable digital scale (the UNICEF electronic weighing scale) after removing shoes and wearing light clothes. The height was measured to the nearest $0.1 \mathrm{~cm}$ in the erect position with their shoulders levelled, hands at the side, and the head, scapula, buttocks and heels in contact with a vertical measuring board with a sliding head bar.

Body mass index (BMI) was calculated by dividing weight in kilograms by height in square metres $\left(\mathrm{kg} / \mathrm{m}^{2}\right)$. The classification of BMI was taken from the WHO standard, that is, $\mathrm{BMI}<18.5=$ 'underweight', $\mathrm{BMI}=18.5-24.9$ $=$ 'normal weight' and BMI $\geq 25=$ 'overweight/obese'. ${ }^{43}$ In the current study, BMI $\geq 25 \mathrm{~kg} / \mathrm{m}^{2}$ is considered as overweight/obese and BMI $\leq 24.9 \mathrm{~kg} / \mathrm{m}^{2}$ is considered as non-overweight/obese.

\section{Measurement of combined OC utilisation}

The exposure variable was combined $\mathrm{OC}$ utilisation. The exposure variable was dichotomized to create a binary variable to reflect either she used combined OC during the survey or not. Women who responded 'Don't know' were excluded. The COC utilisation and other covariates were collected through a questionnaire.

\section{Statistical analysis}

The data were analysed through the IBM Statistical Package for Social Sciences V.22 (Armonk, New York, USA). The frequencies and percentages of the study variables were displayed in tables. Both binary and multivariable logistic regression analysis was conducted to control possible confounders. The Wealth Index was used to measure the household economic status. It is taken from 
Table 1 Sociodemographic and behavioural characteristics of the study sample $(n=11018)$

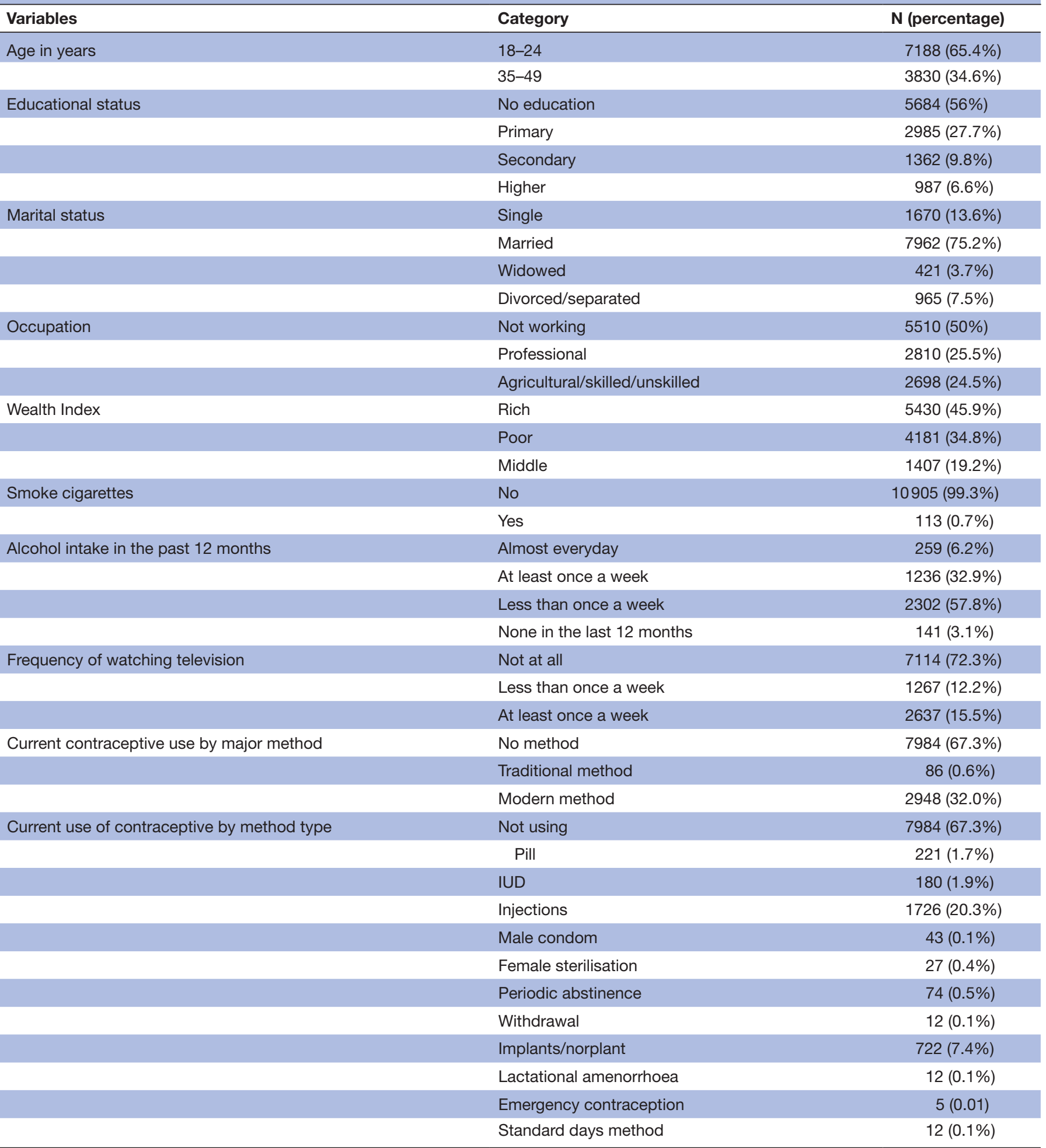

IUD, intrautrine device; N, Number.

the 2016 EDHS and categorised as poor, middle and rich. Adjusted ORs with $95 \%$ CIs were used to declare an association.

\section{Patient and public involvement}

Patients and the public were not involved in this study.

\section{RESULTS}

\section{Participants' characteristics}

The prevalence of overweight/obesity was $8.6 \%$ in the current study. Of the total of 11018 women who participated in the study, $56 \%$ were uneducated and $75.2 \%$ had 
Table 2 Association between OC use and overweight/ obesity among adult women of reproductive age $(n=11018)$

\begin{tabular}{ll}
\hline & Overweight/obesity \\
\cline { 2 - 2 } OC use & OR $(95 \% \mathbf{C l})$ \\
\hline Unadjusted analysis & Ref \\
\hline No & $2.798(1.615$ to 4.85$)$ \\
\hline Yes & \\
Multivariable analysis & Ref \\
No & $1.902(1.064$ to 3.399$)$ \\
\hline Yes &
\end{tabular}

*Adjusted for age, educational status, marital status, occupation, Wealth Index, cigarette smoking status, alcohol intake and watching television.

.OC, oral contraceptive; OR, odds ratio; Ref, reference.

got married. Almost all women had no cigarette smoking history before the survey and more than two-thirds $(72.3 \%)$ did not watch television. Among the participants included in the study $67.3 \%$ did not use any family planning method. Regarding the contraceptive method used, $67.3 \%$ did not use any and $32 \%$ used modern family planning. In the current study the proportion of women who had used combined OC was $1.7 \%$ (table 1 ).

\section{Association between COC use and overweight/obesity}

Generally combined OC utilisation was significantly associated with overweight/obesity. Multivariable logistic regression analysis showed that women with a history of combined OC use had an increased odds of overweight/ obesity after controlling for potential confounders (table 2).

\section{DISCUSSION}

The present study assesses the association between combined OC utilisation and overweight/obesity at the population level in Ethiopia among adult women of reproductive age who participated in the 2016 EDHS. The results showed that there is a positive association between combined OC utilisation and overweight/obesity after controlling for potential confounders.

The current result is supported by ${ }^{44}$ a study among premenopausal girls in Korea; they found that using COC for more than 6 months increased the occurrence of obesity and this was higher among women whose dietary intakes of calcium, phosphorus, potassium, vitamin $A$, vitamin $B_{1}$, vitamin $B_{2}$, niacin, vitamin $C$ and folate were lower than the recommended values. But for those women whose intakes of those nutrients were above the recommended values there was no significant relation between OC use and obesity. Another prospective cohort study among university graduates revealed that prolonged use of OC (more than 2 years) was significantly associated with the development of obesity in the middle-aged and free-living Spanish population. ${ }^{17}$ Additionally similarly findings have been reported in studies conducted elsewhere. ${ }^{14} 1539$

A possible explanation for the observed positive association between combined OC use and overweight/obesity might be hormonal effect of OC that contribute to weight gain. ${ }^{45}$ Indeed; the obesity is mainly due to the pharmacodynamic effects of progesterone and oestrogen. Progesterone increases appetite and results in faster metabolism. Additionally oestrogen facilitates lipid metabolism and fat accumulation in the adipose tissue in the cell. As a result combined OC users are at a risk of developing overweight/obesity. ${ }^{13}$

\section{Limitations of the study}

This study has several limitations. First, the absence of important variables that contribute to obesity, such as intensive physical activity, transportation method and dietary habit in the 2016 EDHS. Second, lack of research papers on the topic makes the discussion difficult. Finally, the cross-sectional design of the present study precludes conclusions regarding a causal link between combined OCs and overweight/obesity.

\section{Conclusion}

In conclusion, the present population-based study supports previous scientific evidence. We conclude that there is a significant association between combined OC use and overweight/obesity among women. The adjusted findings from the present population-based study can be generalised and applied to the entire female population of reproductive age in Ethiopia. The findings have important implications in designing the mechanism for controlling obesity in women. At the national level, the Ethiopian Minstry of Health should give attention for the negative consequences of combined OC on women health since overweight/obesity is another killer of women. It will be better if future researchers conduct a follow-up study to know the real association and provide sound scientific explanations.

Contributors MLE conceptualised, designed, reviewed literature, extracted and analysed the data, and drafted the manuscript. GD, AA and BL analysed the data and reviewed the manuscript. All authors read and approved the final manuscript.

Funding The authors have not declared a specific grant for this research from any funding agency in the public, commercial or not-for-profit sectors.

Competing interests None declared.

Patient and public involvement Patients and/or the public were not involved in the design, or conduct, or reporting, or dissemination plans of this research.

Patient consent for publication Not required.

Ethics approval The data were downloaded once approval was obtained from Measure DHS. The original DHS data were collected in confirmation with international and national ethical guidelines. The 2016 EDHS protocol was reviewed and approved by the Federal Democratic Republic of Ethiopia Ministry of Science and Technology and the Institutional Review Board of ICF International.

Data availability statement The data sets used for this manuscript are available from the corresponding author upon reasonable request.

Open access This is an open access article distributed in accordance with the Creative Commons Attribution Non Commercial (CC BY-NC 4.0) license, which permits others to distribute, remix, adapt, build upon this work non-commercially, and license their derivative works on different terms, provided the original work is 
properly cited, appropriate credit is given, any changes made indicated, and the use is non-commercial. See: http://creativecommons.org/licenses/by-nc/4.0/.

\section{ORCID iDs}

Melese Linger Endalifer http://orcid.org/0000-0003-1505-2500

Gedefaw Diress http://orcid.org/0000-0002-8616-0034

Amanuel Addisu http://orcid.org/0000-0003-3043-1816

\section{REFERENCES}

1 WHO. Obesity and overweight factsheet, 2020.

2 Hruby A, Manson JE, Qi L, et al. Determinants and consequences of obesity. Am J Public Health 2016;106:1656-62.

3 Bray GA. Medical consequences of obesity. J Clin Endocrinol Metab 2004;89:2583-9.

4 Fruh SM. Obesity: risk factors, complications, and strategies for sustainable long-term weight management. J Am Assoc Nurse Pract 2017;29:S3-14.

$5 \mathrm{Ng} \mathrm{M}$, Fleming T, Robinson M, et al. Global, regional, and national prevalence of overweight and obesity in children and adults during 1980-2013: a systematic analysis for the global burden of disease study 2013. Lancet 2014;384:766-81.

$6 \mathrm{Ne}$ al. Overweight and obesity among women: analysis of demographic and health survey data from 32 sub-Saharan African countries (2016). BMC Public Health 2016;16.

7 Goossens GH. The metabolic phenotype in obesity: fat mass, body fat distribution, and adipose tissue function. Obes Facts 2017;10:207-15.

8 Angeliki A, Dimitrios P, Chara T. Maternal obesity and its association with the mode of delivery and the neonatal outcome in induced labour: implications for midwifery practice. Europ J Midwif 2018;2.

9 Adewuyi EO, Auta A, Khanal V, et al. Cesarean delivery in Nigeria: prevalence and associated factors - a population-based crosssectional study. BMJ Open 2019;9:e027273.

10 Maroufizadeh S, Amini P, Hosseini M, et al. Determinants of cesarean section among primiparas: a comparison of classification methods. Iran J Public Health 2018;47:1913-22.

11 Blomberg M. Maternal obesity, mode of delivery, and neonatal outcome. Obstet Gynecol 2013;122:50-5.

12 Evangelista GCM, Salvador PA, Soares SMA, et al. 4T1 mammary carcinoma colonization of metastatic niches is accelerated by obesity. Front Oncol 2019;9:685.

13 Sugiharti S, Hadi H, Julia M. Hormonal contraception as a risk factor for obesity. Med J Indones 2005;14.

14 Mkuu RS, Epnere K, Chowdhury MAB. Prevalence and predictors of overweight and obesity among Kenyan women. Prev Chronic Dis 2018;15:E44

15 Hong SA, Peltzer K, Lwin KT, et al. The prevalence of underweight, overweight and obesity and their related socio-demographic and lifestyle factors among adult women in Myanmar, 2015-16. PLoS One 2018;13:e0194454.

16 Park B, Kim J. Oral contraceptive use, micronutrient deficiency, and obesity among premenopausal females in Korea: the necessity of dietary supplements and food intake improvement. PLoS One 2016;11:e0158177.

17 San-Juan-Rodriguez A, Bes-Rastrollo M, Martinez-Gonzalez MA et al. Oral contraceptives use and development of obesity in a Mediterranean cohort: the sun (Seguimiento Universidad de Navarra) project. Int J Obes 2020;44:320-9.

18 Miller S, Phillips S, Schonberg D, et al. Obesity and the combined oral contraceptive pill: efficacy and effects. Expert Rev Obstet Gynecol 2011;6:477-80.

19 Healthcare FoSR. Overweight, Obesity and Contraception. In: Unit $\mathrm{CE}$, editor. United Kingdom: Faculty of Sexual \& Reproductive Healthcare. 2019.

20 Trussell J, Schwarz EB, Guthrie K. Obesity and oral contraceptive pill failure. Contraception 2009;79:334-8.

21 Edelman AB, Carlson NE, Cherala G, et al. Impact of obesity on oral contraceptive pharmacokinetics and hypothalamic-pituitary-ovarian activity. Contraception 2009;80:119-27.

22 Edelman AB, Cherala G, Munar MY, et al. Correcting oral contraceptive pharmacokinetic alterations due to obesity: a randomized controlled trial. Contraception 2014;90:550-6.
23 Westhoff CL, Torgal AH, Mayeda ER, et al. Pharmacokinetics of a combined oral contraceptive in obese and normal-weight women. Contraception 2010;81:474-80.

24 Simmons KB, Edelman AB. Hormonal contraception and obesity. Fertil Steril 2016;106:1282-8.

25 Robinson JA, Burke AE. Obesity and hormonal contraceptive efficacy, 2014.

26 Brunner Huber LR, Toth JL. Obesity and oral contraceptive failure: findings from the 2002 national survey of family growth. Am J Epidemiol 2007;166:1306-11.

27 Nakajima ST, Pappadakis J, Archer DF. Body mass index does not affect the efficacy or bleeding profile during use of an ultra-low-dose combined oral contraceptive. Contraception 2016;93:52-7.

28 Lopez LM, Bernholc A, Chen M, et al. Hormonal contraceptives for contraception in overweight or obese women. Cochrane Database Syst Rev 2016;79.

29 Cook LS, Pestak CR, Leung AC, et al. Combined oral contraceptive use before the first birth and epithelial ovarian cancer risk. $\mathrm{Br} J$ Cancer 2017; $116: 265-9$.

30 Adeniji AA, Essah PA, Nestler JE, et al. Metabolic effects of a commonly used combined hormonal oral contraceptive in women with and without polycystic ovary syndrome. $J$ Womens Health 2016;25:638-45.

31 Williams MJA, Williams SM, Milne BJ, et al. Association between C-reactive protein, metabolic cardiovascular risk factors, obesity and oral contraceptive use in young adults. Int $\mathrm{J}$ Obes Relat Metab Disord 2004;28:998-1003.

32 Essah PA, Arrowood JA, Cheang KI, et al. Effect of combined metformin and oral contraceptive therapy on metabolic factors and endothelial function in overweight and obese women with polycystic ovary syndrome. Fertil Steril 2011;96:501-4.

33 Gokosmanoglu F, Cengiz H, Varim C, et al. The prevalence of obesity and the factors affecting obesity in the students of secondary education. Int J Res Med Sci 2019;7:2989-94.

34 Al-Raddadi R, Bahijri SM, Jambi HA, et al. The prevalence of obesity and overweight, associated demographic and lifestyle factors, and health status in the adult population of Jeddah, Saudi Arabia. Ther Adv Chronic Dis 2019;10:2040622319878997.

35 Baalwa J, Byarugaba BB, Kabagambe EK, et al. Prevalence of overweight and obesity in young adults in Uganda. Afr Health Sci 2010;10:367-73

36 Addo PNO, Nyarko KM, Sackey SO, et al. Prevalence of obesity and overweight and associated factors among financial institution workers in Accra Metropolis, Ghana: a cross sectional study. BMC Res Notes 2015;8:599.

37 Golshevsky DM, Magnussen C, Juonala M, et al. Time spent watching television impacts on body mass index in youth with obesity, but only in those with shortest sleep duration. J Paediatr Child Health 2020;56:721-6.

38 Narciso J, Silva AJ, Rodrigues V, et al. Behavioral, contextual and biological factors associated with obesity during adolescence: a systematic review. PLoS One 2019;14:e0214941.

39 Al Kibria GM, Swasey K, Hasan MZ, et al. Prevalence and factors associated with underweight, overweight and obesity among women of reproductive age in India. Glob Health Res Policy 2019:4:24.

40 Santos PCD, Silva KSda, Silva JAda, et al. Change in overweight and obesity over a decade according to sociodemographic factors in Brazilian adolescents. Cien Saude Colet 2019;24:3335-44.

41 Firouzbakht M, Esmaeil Riahi M, Hajian-Tilaki K, et al. Relationship of social capital with overweight and obesity among female health care workers. Caspian J Intern Med 2019;10:281-8.

42 Yeshaw Y, Kebede SA, Liyew AM, et al. Determinants of overweight/ obesity among reproductive age group women in Ethiopia: multilevel analysis of Ethiopian demographic and health survey. BMJ Open 2020;10:e034963.

43 Central StatisticalAgency (CSA)[Ethiopia], ICF. Ethiopia demographic and health survey (EDHS), 2016.

44 Park B, Kim J. Oral contraceptive use, micronutrient deficiency, and obesity among premenopausal females in Korea: the necessity of dietary supplements and food intake improvement. PLoS One 2016;11:e0158177.

45 Mody SK, Han M. Obesity and contraception. Clin Obstet Gynecol 2014;57:501-7. 